\title{
Reading nature from a 'bottom-up' perspective
}

\author{
Ola Magntorn and Gustav Helldén \\ Kristianstad University, Sweden
}

\begin{abstract}
This paper reports on a study of ecology teaching and learning in a Swedish primary school class (age 10-11yrs). A teaching sequence was designed to help students read nature in a river ecosystem. The teaching sequence had a 'bottom up' approach, taking as its starting point a common key organism - the freshwater shrimp. From this species and its ecology, the perspective was broadened to involve studies of the interrelations between organisms and finally to the relationship between biotic and abiotic factors. A large part of the instruction took place outdoors. Students were interviewed three times during the course when they were presented with a tray full of objects (both biotic and abiotic) from the ecosystem. The students' task was to name and describe the objects and then to link them up in as many relevant ways as possible, explaining the reasons for the links. The interviews have been transcribed onto concept maps and SOLO-taxonomy was used to illustrate their developing ecological understanding. Results indicate how students related several abstract processes and correlations back to the key organism studied early in the teaching sequence.

Key words: Ecological literacy; SOLO-taxonomy; Concept maps; Field studies.
\end{abstract}

\section{Introduction}

"I know him. He is the freshwater shrimp. $\mathrm{He}$ is very important for the river... he is the cleaner. You know he loves all the dead leaves and so he keeps the river tidy." (Peter, $10 \mathrm{yrs}$, in interview 2).

This quote is from one of the young students who followed a teaching sequence aimed at reading nature in a river ecosystem. The teaching sequence had a 'bottom-up' approach ( $M$ agro et al, 2001) in the sense that it started with the direct contact with an individual species, which was studied in detail. This was followed by studies of its relationships to other organisms and finally to the whole community, and how these were affected by and involved the flow of energy and the cycling of matter in the river.

The ability to read nature is central in this work and needs a brief explanation. We see it as an important aspect of ecological literacy which is ideally about developing a rich knowledge base and multifaceted beliefs and/or philosophies about the environment which lead to ecological sustainability (O rr, 1992). Reading nature focuses on ecology and the context is outdoors. It has to do with an ability to recognise organisms and relate them to material cycling and energy flows in the specific habitat which is to be read. It has to do with the natural world that we face outside; the tools we have are our experiences from previous learning situations both indoors and out-of-doors. In this context it has to do with students' ability to give a relevant interpretation of the river as an ecosystem, based on recognition of common organisms and awareness of their autecology. It also has to do with understanding the relationships between functional groups and how abiotic factors, such as light and the speed of water, influence the whole ecosystem. For further description of the concept see Magntorn and Hellén (2005).

Research on students' learning and understanding of ecology suggests that developing an understanding of ecosystems and their functioning is difficult. Leach and colleagues did a crosssectional study of 5-16 year old students and their understanding of ecology. They found that students do not see the ecosystem as an interrelated whole, i.e. photosynthesis, respiration and decay are not viewed as cycling of matter in ecosystems (Leach et al,1996). A review of the literature suggests that students do not have a good grasp of the complexity in food webs, of energy flow or of the dynamics and structure of ecosystems (e.g. A deniyi, 1985; G allegos et al, 1994; Hogan and Fisherkeller, 1996; Grotzer and Bell Basca, 2003; Carlsson 2002).

This research refers to the upper level of reading nature, with abstract processes and relations. In this study we are also interested students' knowledge of the individual organisms, representing the bottom level in this study. This is often not part of students' common knowledge. This was illustrated when a large sample of 12-14 year olds were asked what sort of living things they would expect to find in freshwater. Frogs, tadpoles and fish were commonly mentioned but few made reference to plants or invertebrates (Lock et al, 1995). 0 ther studies have shown that students have great difficulty in the classification of invertebrates (e.g. Kattman, 2001). Since many of the invertebrates found in a river are insect larvae changing into flying adults, it is also important to know the difficulties young students have with life cycles since they 
tend to forget the egg stage and the cycling of life stages (Shepardson, 2002). From this review it appears that reading nature, with its linking of organisms' ecology to systemic thinking, is a challenging goal to strive for. Its relevance is supported by Slingsby and Barker (1998) when they recommend a 'bottom up' approach, starting with whole organism ecology, in their model of an improved curriculum in ecology education.

\section{Objective}

The main objective is to characterise students' sophistication and ability to read nature as they progress through a teaching sequence designed to develop an understanding of ecosystems via an initial focus on one species.

\section{The teaching sequence and data collection}

The teaching was carried out in a G rade 3-4 class (yrs 10-11) with 23 students. The school is a public school in a small community in southern Sweden. Instruction was carried out by a teacher from the local nature school together with the ordinary class teacher. There was continuous negotiation between the researchers and the teachers about the content and design of the teaching sequence. The overall sequence comprised four phases spanning seven lessons of varied duration from 80 to 200 minutes (see Figure 1).

Space constraints make it necessary to present a short synopsis of the sequence but the authors have made a video highlighting the teaching design and student activities which is available on mms://194.47.25.160/mna/vramsafilmen.wmv. Basically each lesson started with a classroom discussion framing the task to be studied. This was followed by fieldwork along the nearby river and collected material was often brought back to the classroom for further study. The students often worked in small groups and their observations and findings were discussed and summarised in the whole class.

Phase 1 - A utecology (i.e. the ecological relationships of a particular plant or animal species) of the freshwater shrimp ( $G$ ammarus pulex). Collection of the animal in the river was followed by 'brainstorming' when students came up with questions about the shrimp that they could answer by observation or experimentation. Relevant questions and the conclusions from all the observations were discussed.

Phase 2 - Taxonomy (i.e. identification and grouping of animals) and autecology. The children collected different organisms in fast and in slow sections of the stream and studied their adaptation to the environment. Herbivores and predators were determined according to their morphology and behaviour i.e. those with large eyes, large mouth parts and rapid movement are often predators. Life cycles were discussed and seal ed aquatic ecosystems were constructed and discussed according to the 'roles' of plants, animals and abiotic factors such as light and air.

Phase 3 - Synecology (i.e. the ecological relationships of a community). This involved the introduction of food webs and food pyramids based on the organisms observed in the river. A litterbag experiment was conducted where the children put freshwater shrimps and/or the water louse (A sellus aquaticus.) in small net-bags together with green and brown leaves. The bag was then put into the river. After a week it was collected and studied resulting in the discovery that the animals preferred brown leaves and could be considered decomposers in the ecosystem.

Phase 4 - Systemic view (i.e. the relation between biotic and abiotic components and the flow of energy and cycling of matter in the ecosystem). A systemic view of the ecosystem was discussed and students were introduced to photosynthesis and energy flow in the ecosystem by discussing plants ecosystem functions and by building a model of a food pyramid. The sealed ecosystem was opened and examined. The relations between abiotic and biotic factors were discussed and investigated focusing on the importance of water speed, the surrounding environment and the human impact on the river ecosystem.

\section{Research design}

We collected data from three interviews with each student (see Figure 2). We decided to present the interviews as concept maps. The authors have along with many others (e.g. Kinchin, 2000) recognised concept maps as a powerful metacognitive tool for helping students understand complex notions such as ecosystems. But we applied it in its original use by Novak (1998) where he used concept maps to represent large amounts of interview data. A concept map is normally represented in a hierarchical fashion with the most inclusive and most general concepts at the top. W hite and G unstone (1992) defined good maps as those that displayed considerable

Figure 1. The teaching sequence together with the three tray interviews. Interview 1 was conducted in February before the teaching sequence and interview 3 in May, after the teaching sequence.

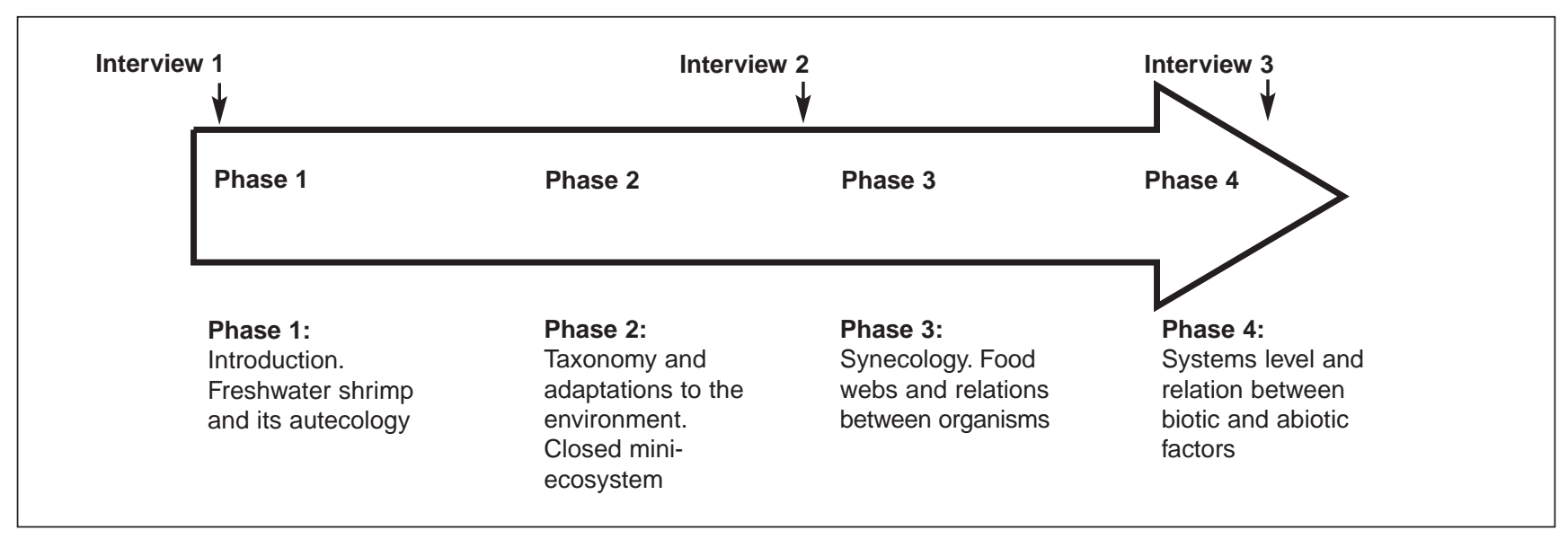


amounts of detail, a variety of types of relations and rich patterns of cross-relations.

We designed an interview method, the tray interview, inspired by ideas from Mellgren (2004). The student was presented with a large tray filled with objects from the river together with pictures of the river and its surroundings. The main interview question was: "Tell me what you think the objects on the tray are and explain how you can link the objects on the tray together in as many ways as possible to explain life in the river?" This resembles the construction of an 'oral' concept map without the paper and pencil work.

The interviews were video-recorded and they were jointly transcribed, rather than interpreted, by the researchers into a concept map. This means that the hierarchy in the map is student-based and reflects the order in which the student chose to mention the objects in the interview. What the student saw as most important is not always what a scientist would suggest. In relation to the bottom-up teaching approach, this means that normally subordinate concepts, such as names of organisms, are presented super-ordinate to more general concepts such as photosynthesis. This is of course mirroring the line of instruction but it also says something about young students' fascination for live animals.

The objects on the tray included a large number of different living invertebrates, representing herbivores, decomposers and carnivores, and both the adult and larval stages of dragonflies. There were also live aquatic plants and brown half-eaten leaves together with pictures of a salmon and of a human. N on-living components were represented such as gravel and rocks from the river bottom together with a glass of water, a dish with air (representing air or gases). Pictures of the sun and of the river in winter and in summer were al so presented to the students. We found that students were encouraged and challenged by the task and the large majority tried hard to link the parts to a whole.

\section{The SOLO analytical framework}

In order to structure our analysis of the tray interviews we have used the SOLO taxonomy ( $D$ art and Boulton-Lewis, 1998; Biggs and Collis, 1982). It offers a model for characterising the levels of sophistication of children's developing explanations. The SO LO taxonomy focuses on sophistication and does not necessarily equate with conventional scientific ideas. The five levels of the taxonomy are described below in the context of ecology.

1. Prestructural. The responses are often inadequate and the student is frequently referring to irrelevant aspects.

2. U nistructural. Single aspects of the task are picked up, but the task itself is not attacked in an appropriate way. The student reasons in the relevant mode but only in single step relations without any mediating description of a sequence of causally linked events or relations. This level of explanation indicates fragmentary understanding without any attempt to make either synthesis or systemic analysis of the ecosystem.

3. M ultistructural. C ausal chains are given in the explanations, linking two or more objects together and referring to relevant ecological theory. There is no attempt, however, to raise the explanations and linking to the level of a generalisation. $\mathrm{No}$ process or abstract relations are discussed.

4. Relational. Relational explanations extend relevant points to a general principle, or interrelationship between factors.

5. Extended abstract. The coherent whole can be generalised on a concrete as well as an abstract level to other ecosystems.

The ability to read nature is related to age and experience and, of course, a biologist reads nature differently from a primary

Table 1. The SO LO -levels in relation to the ecological content knowledge. The SO LO -levels are presented vertically on the left and levels are related to the sophistication and correctness of the ecological categories presented horizontally in the chart.

\begin{tabular}{lll}
\hline SO LO & Autecology + Life cycles & Synecology \\
\hline Prestructural & Trivial single aspect aut-ecological links & No relevant statements regarding how \\
& such as "fish need water". Life cycles & the organisms coexist in the ecosystem.
\end{tabular}
are not discussed in a relevant way.

U nistructural As above but also relevant single aspect links to organisms' morphology or behaviour.

Multistructural Two or more morphological or ecological aspects are linked to separate organisms, often related to their habitat. Life cycle of one or a few organisms is often described.

Relational

As above but several aspects are integrated in a structured and meaningful way describing the relation between single organisms and habitat.

Extended abstract
As above but also single step links between different organisms such as who eats whom.

As above but also linking more than two organisms to a food chain. Recognition of functional groups and their common features

As above but the community of organisms are often linked as in a food pyramid. The importance of plants for the whole ecosystem is recognised. D ifferent life cycles are compared.

As above. Populations are correlated to each other and to the function of the ecosystem. Life cycles are related to variation in biodiversity in the river over the year.
A s above but the student can generalise the link between taxonomy and autecology between ecosystems

\section{Systemic view}

No relevant statements regarding how the biotic and abiotic components make a system with flow of energy and cycling of matter. Parts and whole are not related.

As above but also trivial links between biotic and abiotic components such as all animals need air and light.

As above but also trivial multi-step links between biotic and abiotic components such as plants need gravel and light to grow and shrimps must eat them, otherwise there are too many

Energy flow in ecosystems is described linking the sun with plants and consumers. The shrimp is related to wate quality. Cycling of matter is not discussed.

As above but there is some generalisation between the river and the sealed ecosystem or other ecosystems. G eneral conclusions about energy and cycling of matter are drawn. 
school student. The principles on which the interview data were assigned to the five SO LO -levels mainly hinged around the sophistication of causal notions within - as well as between - the categories of autecology, synecology and systemic thinking (see Table 1). The table is the result of analysing tray interview data over and over again, searching for patterns of significant developmental steps towards relevant complex thinking of the river as an ecosystem. The table should be read horizontally: for example, a student on a relational level of reading the river has reached this level on all three categories. These SO LO-levels are based on our interpretation of the total interview material.

\section{Results}

Figure 2 illustrates students' developing ability to read nature. The development itself is no surprise, especially not since the SO LO -categories are based on the interview material. W hat is of greater interest, though, is the qualitatively different ways they read nature in the later interviews. Initially all students had a limited ability to link the objects on the tray. They did not know the names of most organisms and they knew very little about their autecology. In the second interview all students related objects to the autecology of the freshwater shrimp and how this in turn related to a few other organisms in the river. Life cycles, adaptations to waterflow and trophic relations were discussed on a multi-structural level by the majority. Two students related the autecology to processes in the river such as the importance of plants for all life in the river.

In the third interview, as in the previous, most students started by describing the freshwater shrimp and its autecology. They often added synecological and systemic relations linking it to water quality, trophic relations and energy in the ecosystem. Fifteen students read the river on at least a relational level, where they linked the organisms to the function of the ecosystem. To illustrate the developing ability to read nature we selected two students, A nna and Peter, whose interviews will be presented as concept maps together with short excerpts of their comments. In general, their developing ability to read nature corresponds with the majority of the students but they were also chosen since they appreciated different parts of the teaching content.

\section{The developing ability to read nature of Anna and Peter}

The teacher, with 30 years of teaching experience, described her class as "a positive class but there are no really strong students and as a whole I believe the class is about average".

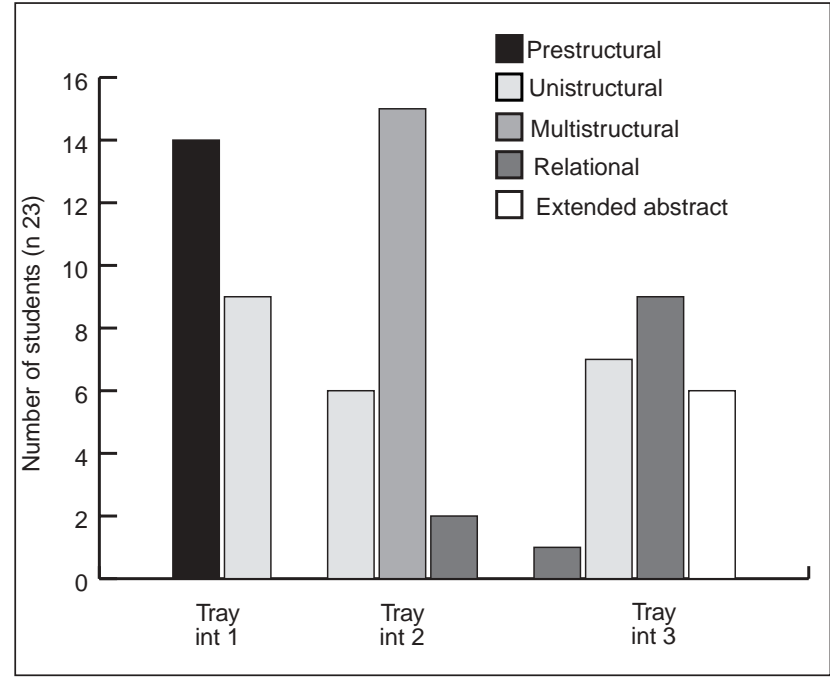

Figure 2. The number of students reaching the different SOLO-levels in tray interviews 1, 2 and 3.

Prior to instruction she described A nna as "quite lazy but good at logical thinking" and Peter as "interested in most things and good at observation". Peter said he had been fishing in the river a few times, but apart from that both students said they had no prior experience of studying life in a river.

Initially they showed a very limited ability to read nature, citing mainly single step and often trivial relations between the objects. There were generally no cross-links and they always started with the organisms. As indicated in the concept map (Figure 3) Anna's species knowledge was restricted to fish, dragonflies, mussels, snails and seaweed. The structure of the concept map reveals a limited ecological understanding involving only a few species.

Teleological reasoning was common, such as regarding the sun as important for visibility or the water as important for animals to swim in. Reasoning about the functions of the organisms in relation to whole ecosystem was largely absent. This was not surprising and is supported by other studies of novices describing ecosystems: $\mathrm{H}$ melo-Silver and $\mathrm{G}$ reen-Pfeffer (2004) showed that 13-14 year old students, when asked to describe and explain an aquarium, mainly described structures such as fish or water without mentioning the functions of the biotic and abiotic components and how they interacted.

In the first interview it was al ready apparent that A nna and Peter had slightly differing foci when reading nature. A nna was more interested in finding generalisations from single observations. O ne example of this was when she said that fish had gills for breathing and that they breathed air in the

Figure 3. Anna's tray interview 1. The concept map contains concepts marked with different symbols for indicating the taxonomic level (ellipse) and autecological level (rectangle). The concept map is the researchers' interpretation of her interview.

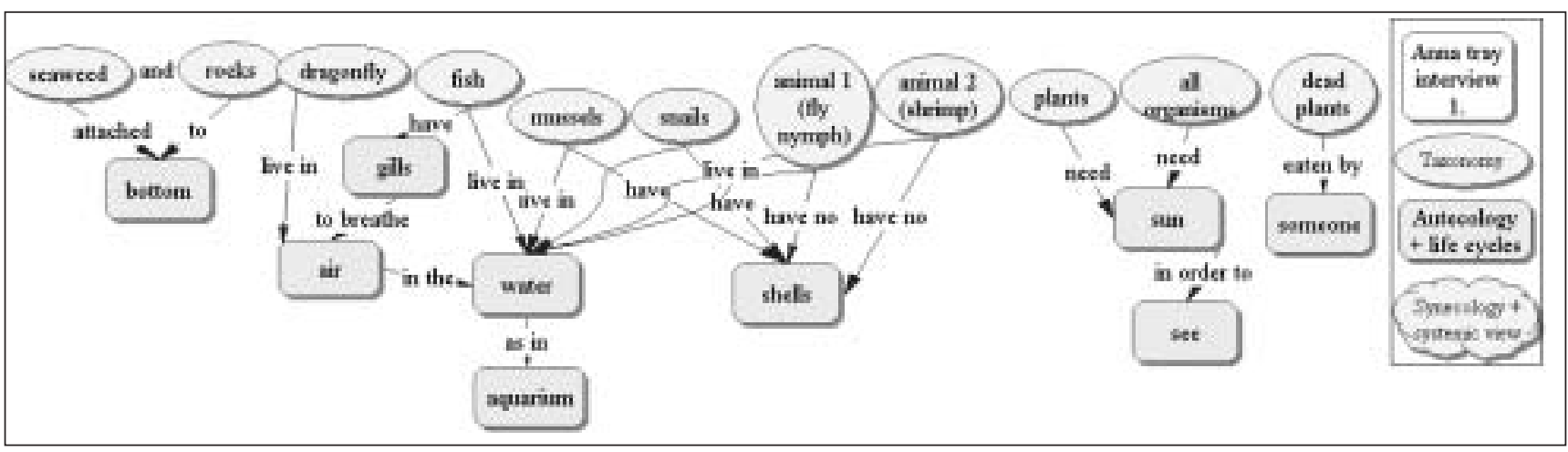


water as they do in an aquarium. Peter on the other hand was more interested in the details and he did not generalise his observations to other relevant situations as much as A nna did. He often presented narratives and one example was his observation of the dragonflies when he was fishing. He said:

I have seen them when they land on the water and they

take up something, maybe water. They take it until they turn red and then they fly away again. Yes I have seen that" (Peter interview 1).

This statement, despite its factual error, illustrates Peter's curiosity about the animals and their behaviour. We classified A nna's ability to read nature as prestructural and Peter's as unistructural. The difference between them was that Peter linked several different organisms e.g. saying that the salmon can eat different animals, pointing at the shrimp and the water louse.

In the second tray interview, both students started by describing the shrimp and its autecology. A nna's links were mainly of an ecological character such as how it breathed and where in the river she found it. She also added its role as a cleaner, eating dead plants. Peter on the other hand mainly linked morphological rather than ecological characteristics to it. They both discussed life cycles and Peter described life cycles of both dragonflies and stoneflies. He was fascinated by the resemblance between their larval and adult stages. A nna compared the shrimp and the dragonfly saying that they either have full metamorphosis as the dragonfly or no 'real' metamorphosis as the shrimp.

Peter found it challenging to name all the organisms and he identified more organisms but made fewer autecological links to them than A nna did. They both linked the morphology of herbivores and carnivores to typical animals they had found in the river. Peter's strong interest in morphological details is exemplified by a typical statement when he was looking at a caddis larvae with a flat case made of small stones.

Peter: Yes this is with a house made of stones - I know it must live in the fast stream. So, you have been out in the fast stream catching it, haven't you?
Interviewer: O K. How do you know?

Peter: Yes, well otherwise it would just be washed away.

A $n$ example of A nna's stronger interest in systemic relations rather than in the different life forms could be seen when she tried to link the plants and the decomposers present in the excerpt below.

A nna: Well the shrimps and the water lice eat the dead leaves and that is food, kind of, and then it comes out as faeces.

Interviewer: O K. A nything else?

A nna: Yes, it is washed out in the river and maybe the plants will have it again as fertilisers or something, I'm not sure

Synecological links were still very infrequent and were often trivial and incorrect. For example, the relation between the plants and solar energy (and its importance for the ecosystem) was mentioned by very few students, including A nna, but the process of photosynthesis was unfamiliar to them all. Both A nna's and Peter's ability to read nature in the second interview were classified as multistructural.

In the third tray interview most students, including Peter, start with the shrimp and its autecology. This is interesting since the teaching focus is no longer on the shrimp but on synecological processes including the shrimp. The links are now more of ecological rather than morphological in character as exemplified by the excerpt below.

Peter: It eats old leaves and therefore it kind of cleans the river and that's good for all the others.

Interviewer: A ha?

Peter: I know that because we made an experiment and we put them and the water louse in a bag and they got a green and a brown leaf. Then we walked down to the river and put them in the water. We walked down again after a week and then we saw that they had only eaten the brown, rotten leaves.

Peter's experience of the episode with the shrimps is mirrored by A nna's In her concept map she considers the feeding preferences of the shrimp. Both relate the shrimp to water

Figure 4. Anna's tray interview 2. The concepts are indicated with different symbols representing taxonomic level (ellipse), autecological level (rectangle) and (cloud) systemic and synecological level. The freshwater shrimp was her starting point and she related it to several autecological features.

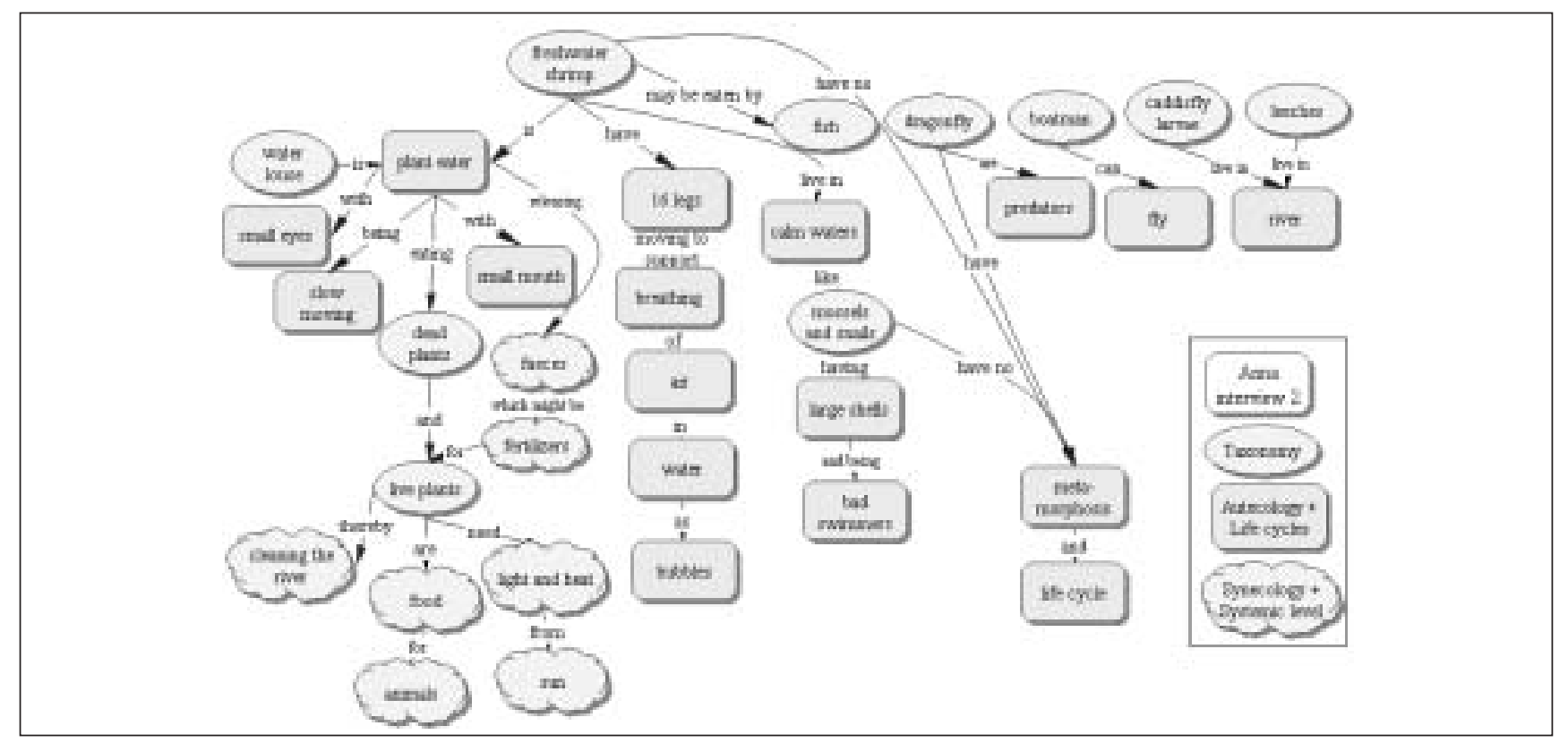




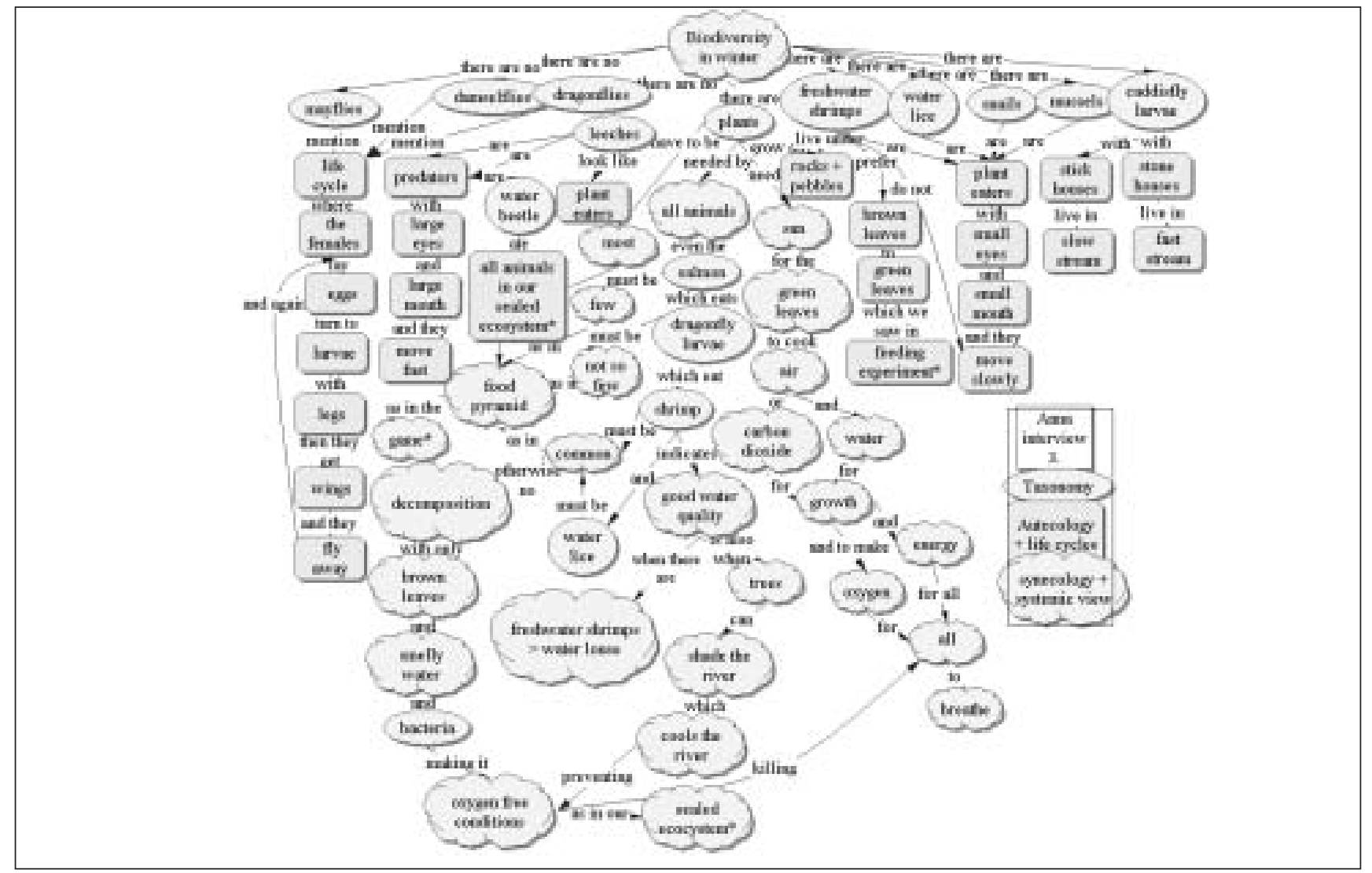

Figure 5. Anna's tray interview 3. Concepts are marked with different symbols representing taxonomic level (ellipse), autecological level (rectangle) and systemic and synecological level (cloud). * refer to items in the formal instruction.

quality, saying that finding more shrimps than water lice means the water quality is good. Peter recognises all the invertebrates in the tray and says he has made drawings of most of them in his schoolbook. Anna recognises fewer of the invertebrates but on the other hand she expresses more ecological links to each one of them. A $n$ example of the different focus can be illustrated by the following links to the same animal. Peter says:

Peter: That one is a leech. I know there are two species of them and they move from one stone to another like this (shows their locomotion with his fingers).

A nna: L eeches are also predators but they don't look like it. They suck blood.

Peter is an observer and notices animal behaviour whereas A nna is more interested in their function. Both of them discuss adaptations to the environment. Along with a majority of students they also mention the sun and its importance for the plants and subsequently for the whole ecosystem. Peter is more restricted to the model presented by the teacher where plants, shrimps, dragonfly larvae, salmon and humans are parts of the food pyramid, saying that there need to be mostly plants for the energy to support the top predators. A nna general ises from this model and adds new organisms to it without losing the main idea. The excerpt below illustrates A nna's synecological views about the importance of plants for all other organisms.

A nna: "it will be oxygen, some oxygen which everyone can breathe. And they need those stones since they grow on them and dragonfly larvae need animals, oxygen and light so they see and then the shrimps and all other plant eaters need leaves to eat which, er, need the sun and all that I said before So it's kind of connected. Everyone needs air from the plants yes everyone is connected with the plants even the salmon which eats such, er, dragonflies so everything has to be there

This excerpt illustrates a systemic level of reasoning which both students have, but A nna is more elaborate. In the short excerpt below A nna refers to the principle of too many predators resulting in too few shrimps and water lice in the river. She exemplified systemic reasoning with her recollection of an experiment with the sealed ecosystem where it turned anoxic and very smelly after a few weeks.

A nna: Yes there has to be mostly leaves. Yes, since they have to eat all the leaves and there are so many mayfly larvaeand shrimps. Yes, otherwise there is not enough food for the salmon who have to eat many dragonfly larvae every day... We played the game which showed that

Interviewer: $0 \mathrm{~K}$, but how can it be too many of these (points at dragonfly larvae).

A nna: Yes, then the shrimps and water lice would have been extinct and then it would only have been a lot of dead leaves and bacteria and no air in the water. The river would probably have smelled bad just like our "river in a jar" [sealed ecosystem] did. There all animals died and there were lots of bacteria breathing all the oxygen.

They eat a lot and they breathe a lot so they finish the oxygen.

Both Peter and Anna often referred to episodes from the outdoor activities or hands-on experiments and classroom observations when they discussed complex relations on synecological or systemic level. It is interesting to see how they developed their ability to read nature over the course. Peter's strong interest in taxonomy and autecology was his focus and when he read nature it was a rich story about the life and life 


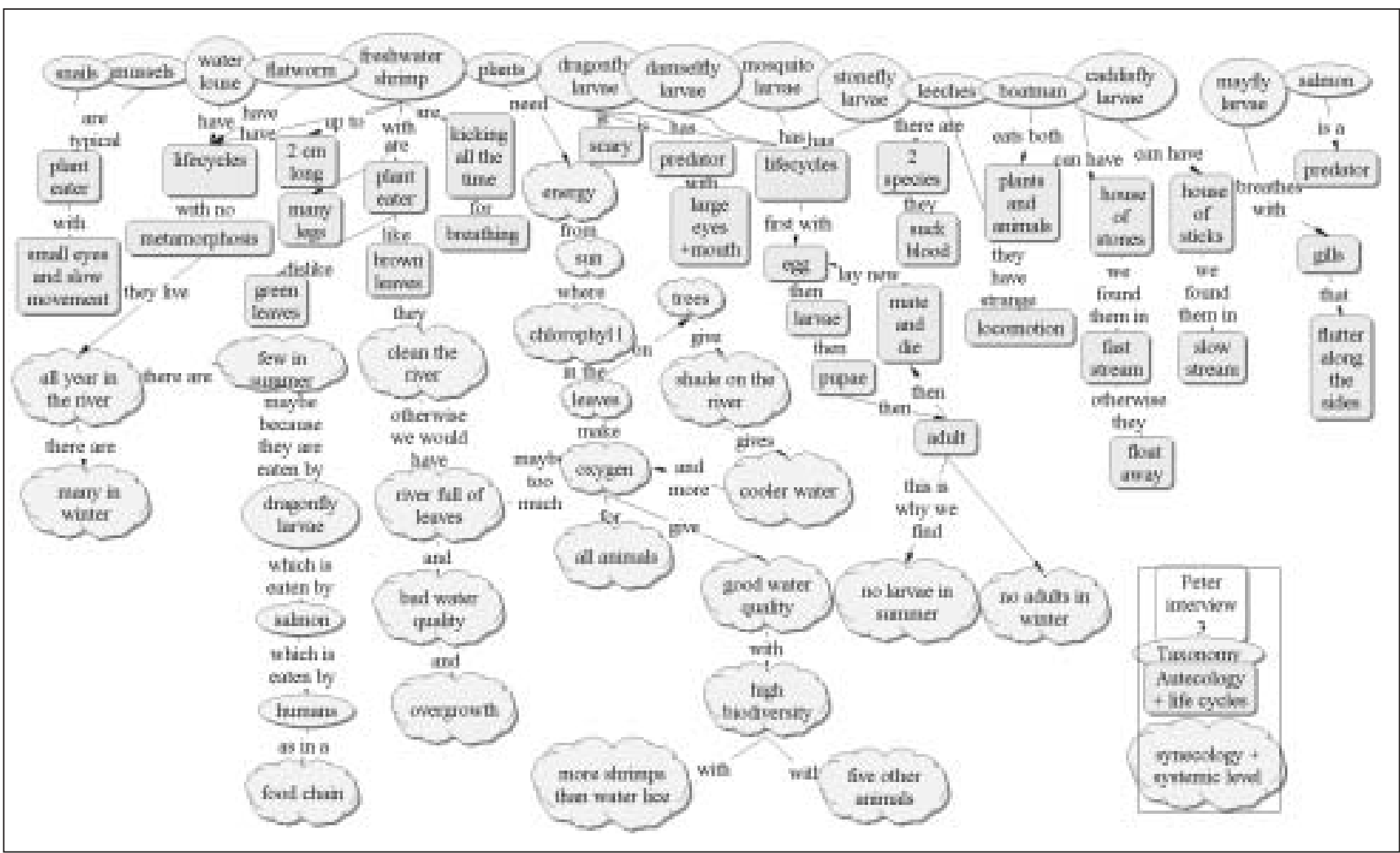

Figure 6. Peter's tray interview 3. Concepts are marked with different symbols representing taxonomic level (ellipse), autecological level (rectangle) and the systemic and synecological level (cloud).

forms in the river. This is mirrored in his concept map from interview 3 (Figure 6). The upper part with taxonomy and autecology is very dense but the links to the systemic levels are not so rich. A nna on the other hand had never been very interested in the animals but she used her knowledge of taxonomy and autecology to link the animals to a more systemic reading of nature than Peter did.

In her concept map from the third interview she had more synecological/systemic sections (i.e. links and concepts together) and she read nature on an extended abstract level where she generalised her ecological ideas from experiments and specific experiences during the teaching sequence. She says she is thinking about questions such as "how can they survive here and what are their roles in the ecosystem functioning?" Peter has also greatly developed his ecological thinking over the course but he is more restricted to the links he has heard about and his focus is on the upper parts of the concept map where the species knowledge and autecology is in focus. $\mathrm{He}$ reads nature on a relational level.

\section{Discussion and implications for teaching}

Underlying the whole design of this study is curiosity about how students relate the individual species to the whole ecosystem. Prior to instruction, all students had very little knowledge of the organisms in the river. This lack of taxonomic knowledge is supported by earlier research (e.g. Lock et al, 1995) and since reading nature has to do with linking taxonomy to ecosystem processes they were often struggling to find something to say in the first interview. The importance of taxonomy was mentioned by the Swedish eighteenth-century scientist Linnaeus. He wrote "N omina nescis perit et cognita rerum" (If we don't know the names the knowledge of the things themselves is worthless)(Linnéus, 1737). His point was that of communication and how crucial it is to have common names for organisms in order to avoid confusion and to be able to discuss natural history.

We started with an in depth study of the shrimp in order for the students to find out as much as possible about its morphology, behaviour and autecology. This type of inquirybased study of a single organism, has in other studies been shown to be highly motivating for the students (e.g. Tomkins and Tunnicliffe, 2001). It was followed by identification of other organisms and their adaptation to life in the river. In interview 2, every student had something to say about the shrimp and most students could mention at least five different invertebrates and link them to their autecology. Taxonomy and autecology was linked by statements like "x lives in fast streams and has a flat body" or to the life cycles of different organisms; this resulted in single step chain structures in the concept maps indicating limited integrated knowledge. If we look at the Swedish curriculum, though, this is what ecology education should strive for. It says that students should after their fifth school year "recognise and be able to name common plants, animals and other organisms in the local environment, as well as be familiar with their environmental requirements" (N ational Agency for Education, 2007).

We could justifiably say that instruction has met the curricular demands, but what use is this for an ecological understanding? They are still far from readers of nature. From our point of view this knowledge is a good starting point for learning synecology where they have to see the shrimp as part of a larger system. The last interview showed that eight students did not reach a relational level which is required for synecological reasoning. These students referred to the shrimp and some of its autecology but they did not link it to relevant synecology. The move from the concrete to the more abstract 
is of course difficult to do but it could also be related to the interview format which does not require that they explicitly discuss the synecology. The others related the shrimps, the plants and some other organisms in synecological discussions such as exemplified by A nna and Peter. It is also worth mentioning how the design of instruction has allowed both Peter's interest for naming and A nna's interest for processes to develop.

O ne of the main conclusions from our study is the importance of autecological knowledge. We see it as the glue between taxonomy and systems ecology. Knowing the names and the often fascinating autecology can build an interest for learning more about the mechanisms supporting the life in the ecosystem and the relations between populations. The affective component is important and, as an example, M agro et al (2001) have shown that teaching ecology from a top-down approach starting with the ecosystem and not relating to the individual species has led to students losing interest and regarding the "teaching of ecology as cut off from real life and of poor appeal to pupils".

\section{Final remark}

In a review of concept development and progression within ecology teaching, Barker and Slingsby (1998) claim that a serious barrier to the teaching of ecology is the over-emphasis on sophisticated concepts, combined with a failure to allow a knowledge of whole-organisms biology to progress. They recommend a 'bottom-up' approach. We agree and in the design of our teaching sequence we have tried to meet some of their demands. What we want to stress is the idea underlying the whole idea of teaching for reading nature: that is the importance of fieldwork. Dillon et al (2006) write about the growing concern for the decreasing opportunities for fieldwork in schools and they claim that evidence from research from all around the world shows that fieldwork can have a range of beneficial impacts on participants. H owever, it needs to be carefully planned, thoughtfully implemented and followed up back at school. The curriculum in Sweden does not stress the importance of fieldwork, but adding the ideas of reading nature to the curriculum is a way of meeting the demands not only from science education research but also, at least in Sweden, of the many voices in the public debate expressing anxiety and strong concern about lack of fieldwork and growing ecological illiteracy.

\section{References}

A deniyi E O (1985) M isconceptions of selected ecological concepts held by some Nigerian students. Journal of Biological Education, 19, 311-316.

Barker S and Slingsby D (1998) From nature table to niche: curriculum progression in ecological concepts. International Journal of Science Education. 20(4) 479-486.

Biggs J and Collis K (1982) Evaluating the quality of learning: The SO LO Taxonomy. N ew York A cademic Press

Carlsson B (2002) Ecological understanding 1: ways of experiencing photosynthesis. International Journal of Science Education. 24(7) 681-699.

D art B and Boulton-Lewis G (1998) Teaching and Learning in higher Education. Australian Council for Educational Research.

Dillon J, Rickinson M, Teamey K, M orris M, Choi M Y, Sanders D and Benefield P (2006) The value of outdoor learning: evidence from research in the UK and elsewhere. School Science Review. 87(320) 107-113.

Gallegos L, Jerezano M E and Flores F (1994) Preconceptions and relations used by children in the construction of food chains Journal of Research in Science Teaching, 31 259-272.

G rotzer T A and Basca B (2003) How does grasping the underlying causal structures of ecosystems impact students' understanding? Journal of Biological Education 38(1) 16-29

Hogan K and Fisherkeller J (1996) Representing students thinking about nutrient cycling in ecosystems. J ournal of Research in Science Teaching, 33(9) 129-141.

H melo-Silver C E and Green Pfeffer M (2004) Comparing expert and novice understanding of a complex system from the perspective of structures, behaviours, and functions. C ognitive Science, $\mathbf{2 8}$ $127-138$

Kattman U (2001) A quatics, Flyers, C reepers and terrestrials - students conceptions of animal classification. Journal of Biological Education 35(3) 141-147.

Kinchin I M (2000) Concept mapping in biology. Journal of Biological Education, 34 61-68.

Leach J, D river R, Scott P and Wood-Robinson C (1996) Childrens ideas about ecology 2: ideas found in children aged 5-16 about the cycling of matter. International J ournal of Science Education, 18(1), 19-34.

Linnéus C (1737) C ritica Botanica No 210. In Ellenius, A. (1998) $\mathrm{N}$ aturen som livsrum. N atur\& Kultur. Stockholm.

Lock R, Kaye D and M ason H (1995) Pupil perception of local habitats. School Science Review, 76(277) 57-60.

Magntorn $O$ and Helldén G (2005) Student-Teachers' A bility to Read Nature: Reflections on their own learning in ecology. International Journal of Science Education 27(10) 1229-1254.

M agro A, Simmoneaux L, N avarre A and Hemptinne J-L (2001) The teaching of ecology in the agricultural secondary curricula in France: a new didactic approach. In Proceedings of the III Conference of European researchers in Didactics of Biology. September 27O ctober 2. Santiago de Compostela 197-205.

M ellgren I (2004) Brickan som en resurs i undervisningen. (Tray as a resource in education) $\mathrm{Bi}$-lagan. Nationellt resurscentrum för biologi och bioteknik. No 3.Uppsala University, Sweden.

N ovak J D (1998) Learning, creating and using knowledge. M awhah, $\mathrm{NJ}$ : L awrence Erlbaum Associates.

O rr D W (1992) Ecological Literacy: education and the transition to a postmodern world. A Ibany State University of N ew York

Shepardson D P ( 2002) Bugs, butterflies and spiders: children's understanding about insects. International Journal of Science Education, 24(6) 627-643.

Tomkins S P and Tunnicliffe S D (2001) Looking for ideas: observation, interpretation and hypothesis-making by 12 year-old pupils undertaking science investigations. International J ournal of Science Education 238 791-813.

White R and Gunstone R (1992) Probing U nderstanding. London: Falmer Press

\section{Web reference}

$N$ ational Agency for Education. (Accessed 31.01.2007) www 3. skolverket.se/ki03/front. aspx?sprak =EN \&ar $=0607$ \&infotyp=24\&skolform=11\&id=3879\&extral d=2087

O la Magntorn (corresponding author) is lecturer in the D epartment of Mathematics and Science, Kristianstad U niversity, SE-291 88 K ristianstad, Sweden. Tel: + 4644 -20 34 40. Fax: 4644 - 2034 03. Email: ola.magntorn@mna.hkr.se. G ustav Helldén is professor in the same department. Email: gustav.hellden@mna.hkr.se 